\title{
JUURNAL.RU
}

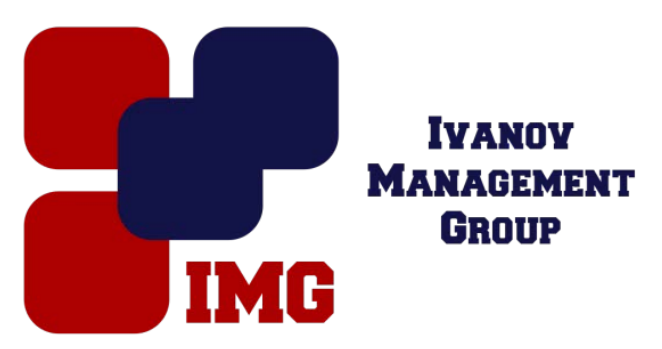

Герасименко Е.Ю., Петренко А.И., Кобец В.А. Донской Государственный Технический Университет Ростов-на-Дону, Россия

doi: 10.18411/lj-30-11-2016-3-06

idsp 000001:lj-30-11-2016-3-06

\section{Система управления установкой электролиза с программируемым качеством катодного покрытия}

\section{Аннотация}

В данной работе определяется система управления установкой электролиза с программируемым качеством катодного покрытия,была получена кривая напряжения на регуляторе.

Ключевые слова: электроосаждения благородного металла, электролизер.

Целью работы является построение системы управления, обеспечивающей получение заданного металлического покрытия на катоде электролизера с определенными функциональными свойствами.

Относительно лимитирующей стадии электродных процессов данная система (электролизер) с электротехнической точки зрения будет представлять собой активный нелинейный двухполюсник (рис. 1).

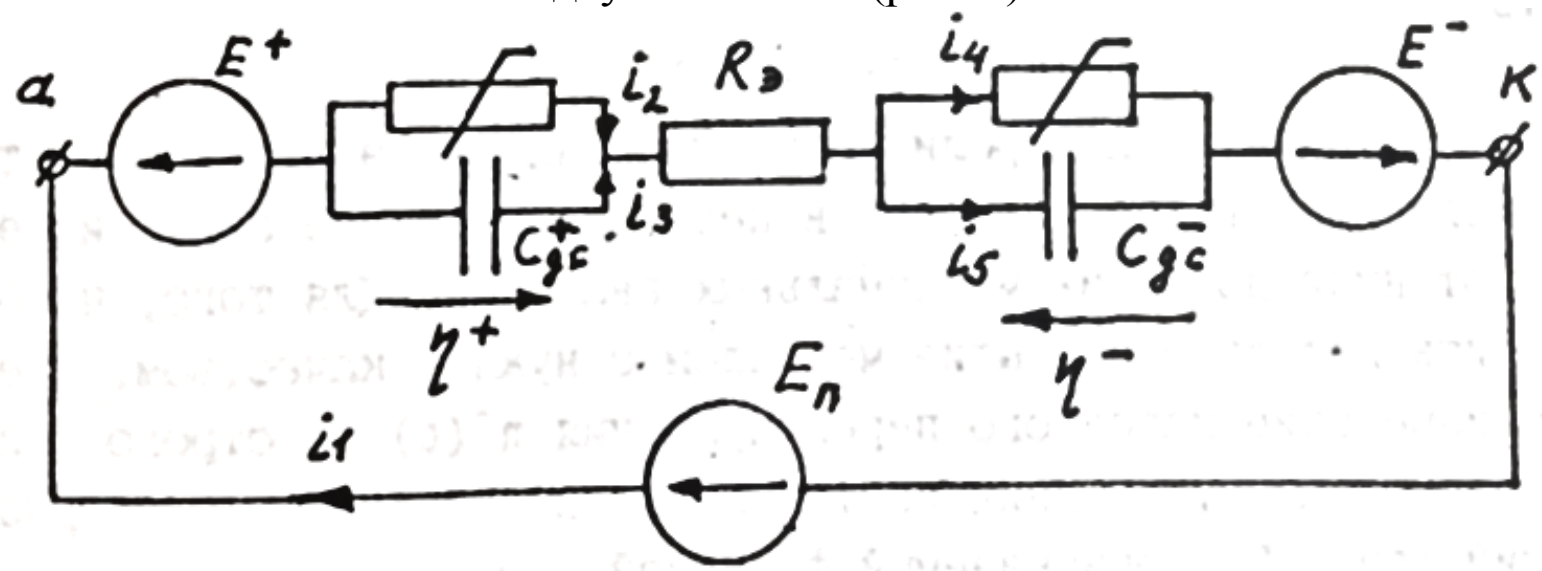

Рис. 1. Пассивное включение электролизера

Чтобы в электролизере на катоде начались процессы электроосаждения благородного металла (платины),необходимо замкнуть внешнюю цепь а-к на 
внешний источник электрической энергии, например, источник напряжения с э. д. с. Еп.

Токораспределение в этой схеме описывается уравнений Кирхгофа

$$
\begin{aligned}
& \left\{\begin{array}{l}
i 1-i 2-i 3=0, \\
i 4+i 5-i 1=0, \\
\eta^{+}=\frac{1}{C_{g c}^{+}} \int_{0}^{t} i 3 d t, \\
-\eta^{-}=\frac{1}{C_{g c}^{-}} \int_{0}^{t} i 5 d t
\end{array}\right. \\
& i 2=i^{+} 0 S^{+}\left[e \frac{\alpha^{+} Z^{+} F}{R T} \cdot \eta^{+}-\frac{\left(1-\alpha^{+}\right) Z^{+} F}{-e} \cdot \eta^{+}\right] \text {, } \\
& i 4=i^{-} 0 S^{-}\left[-\frac{\alpha^{-} Z^{-} F}{e} R T \cdot \eta^{-} \frac{\left(1-\alpha^{-}\right) Z^{-} F}{-e} \cdot \eta^{-}\right], \\
& i 1 R_{\ni}+E^{+}+\eta^{+}-E^{-}-\eta^{-}=E_{\Pi},
\end{aligned}
$$

где $\mathrm{S}+, \mathrm{S}-$-площади анода и катода соответственно.

В системе (1)-(7) начальные условия полагаются нулевыми, то есть

$$
\eta^{+}(0)=0 ; \eta^{-}(0)=0 \text {. }
$$

Если замкнуть электролизер на постоянную э. д .c. ЕП, то перенапряжения $\eta^{-}(\mathrm{t})$ и $\eta^{+}(\mathrm{t})$ в переходном режиме будут меняться от нуля до своих максимальных значений. Чтобы обеспечить катодное покрытие металлом с нужным необходимым качеством, требуется изменение катодного перенапряжения $\eta^{-}(\mathrm{t})$ по строго определенному закону. Одним из таких законов может быть апериодический (рис. 2), описываемый функцией

$$
\eta^{-}(\mathrm{t})=\mathrm{Ate}^{-\beta \mathrm{t}}
$$

где параметры А и $\beta$ являются заданными величинами. В настоящей работе это

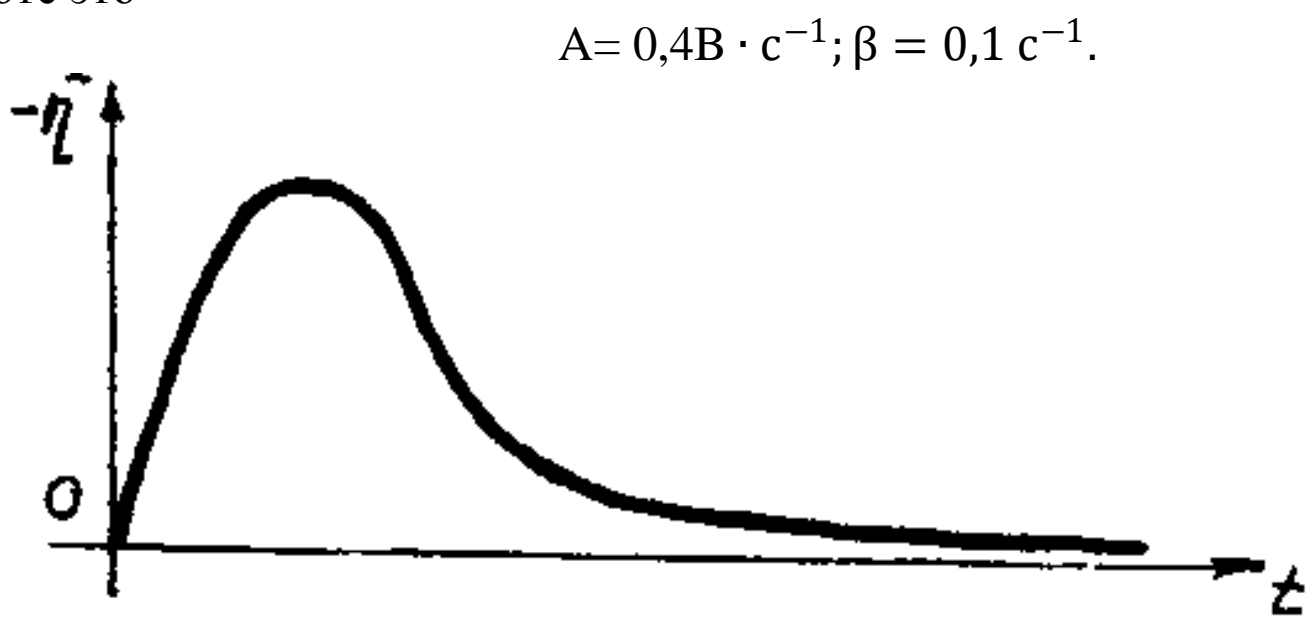

Рис. 2. Кривая катодного перенапряжения 
Для достижения цели - воспроизведения нужного закона катодного перенапряжения $\eta^{-}(\mathrm{t})$ - в схему на рис. 1 последовательно с э. д. с. Еп необходимо ввести (рис.3) регулятор с напряжением $U p(t)$.

Введение регулятора влечет изменение уравнения (7):

$$
i_{1} R_{\ni}+E^{+}+\eta^{+}-\left(E^{-}+\eta^{-}\right)+U_{p}=E_{\Pi} \text {. }
$$

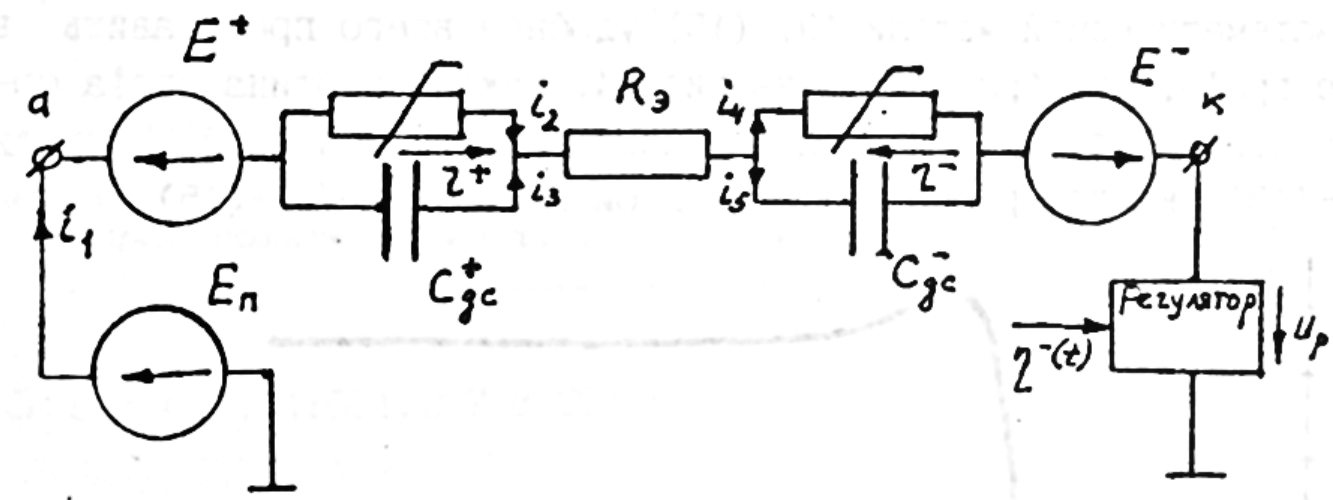

Рис. 3. Программное управление электролизером

Математическая модель (1)-(6), (8) дает возможность раскрыть структуру последовательного регулятора. Будем исходить из того, что на вход регулятора воздействует заданное катодное перенапряжение $\eta^{-}(\mathrm{t})$, а на выходе должно соблюдаться напряжение $\mathrm{U}_{\mathrm{p}}(\mathrm{t})$. Под это требование и преобразуется полученная модель (1)-(6), (8):

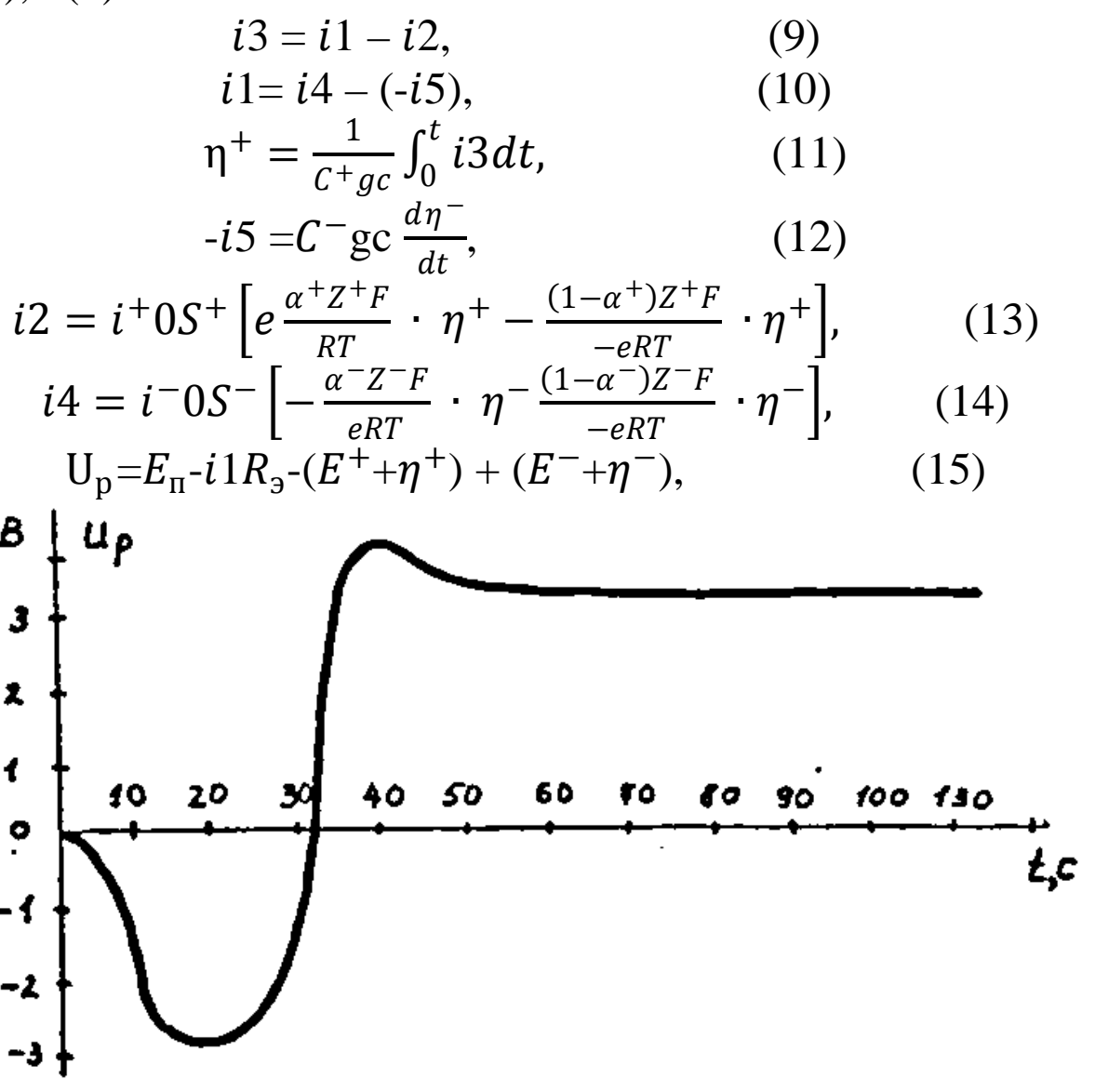

Рис. 4. Кривая напряжения на регуляторе 
Поскольку разработанная система управления имеет нелинейности, то исследование ее динамики аналитическими методами практически исключено. Наиболее удачным методом решения этой задачи является ее реализация в системе MASS [1] на ЭBМ типа IBM. Данная система по существу является аналого-цифровым комплексом, где оптимально использованы достоинства цифровых и аналоговых вычислительных машин. При исходных данных

$$
\begin{gathered}
Z^{-}=3 ; \alpha^{-}=0,5 ; i^{-} 0 S^{-}=0,48 \times 10^{-3} \mathrm{~A} ; C^{-} \mathrm{gc}=0,4 \times 10^{-4} \phi ; \\
Z^{+}=2 ; \alpha^{+}=0,5 ; i^{+} 0 S^{+}=0,50 \times 10^{-3} \mathrm{~A} ; C^{+} \mathrm{gc}=0,4 \times 10^{-3} \phi ; \\
R_{3}=1,2 \mathrm{OM} ; E^{-}=0,45 \mathrm{~B} ; E^{+}=1,229 \mathrm{~B} ; E_{\mathrm{\Pi}}=5 \mathrm{~B}
\end{gathered}
$$

Была получена вышеприведенная кривая напряжения на регуляторе. 


\section{Литература}

1. Методические указания по использованию диалогового пакета прикладных программ для анализа и синтеза динамических систем. / Сост.: Пятина О.Н., Галикян Г.С., Малашенко Л.И.:Новочерк. политехн. ин-т. Новочеркасск, 1989. 38 с. 